\title{
Appendicectomies at a tertiary hospital: disease profile and surgical practices at Grey's Hospital, Pietermaritzburg
}

\author{
Nkomba C Kalenga ${ }^{1 *}$, Polycarpe N Makinga ${ }^{2}$ and Lucien C Ferndale ${ }^{1}$ \\ 1Department of Surgery, Grey's Hospital, South Africa \\ 2Department of Family Medicine, Ladysmith Hospital and University of KwaZulu-Natal, South Africa
}

Submission: February 19, 2017; Published: March 03, 2017

*Corresponding author: Nkomba C Kalenga, Department of Surgery, Grey’s Hospital, South Africa, Email: Christophe_kalenga@yahoo.fr

\section{Abstract}

Introduction: The cause of acute appendicitis is probably multifactorial, and perforation may occur as the disease progresses. Appendicectomy is the treatment of choice and is increasingly being performed laparoscopically.

Objectives: To determine the patients' demographic and clinical characteristic, the commonest surgical approach, the prevalence of diagnostic inaccuracy and the association between perforated appendicitis and gender and age.

Methods: A retrospective review of the medical records of 196 patients diagnosed with appendicitis at Grey's hospital over an 18-month period was conducted. Data was collected on demographics, surgical approach, histology findings and complications.

Results: Of the 196 patients, the mean age was 21.1 years, 54\% were perforated, and the incidence of complicated appendicitis was highest at the extreme ages. Three surgical approaches were used: midline laparotomy (61.7\%), Lanz incision (27.6\%) and laparoscopy $(10.7 \%)$. Bowel resection with primary anastomosis and stoma formation were done on $1.5 \%$ and $0.84 \%$ of cases respectively, while the abdomen was left open in $3.6 \%$ of cases. Although laparotomy was used for suspected perforated appendicitis, a small percentage of those who had midline laparotomy were, intraoperatively, found to have non-perforated appendicitis. Laparoscopic surgery was only used in a few selected cases of non-perforated appendicitis. The overall post-operative ICU admission was $9.7 \%$.

Conclusion: The majority of cases were perforated appendicitis. Midline laparotomy was the most preferred surgical approach despite its associated morbidities. Laparoscopy was the least frequently utilized approach in this tertiary health facility.

Keywords: Appendicectomy; Appendicitis; Perforated appendix; Surgical approach; Tertiary Hospital

\section{Introduction}

Appendicitis is one of the commonest causes of abdominal pain in both genders, occurring more often younger people [1], with the gender predominance varying across regions $[1,2]$. The causes of this disease are not clear, with several pathophysiological hypotheses having been proposed. The dietary fiber hypothesis suggests that the disease may be caused by the consumption of a low fiber diet. The hygiene theory suggests that improvements in water supply and sewerage disposal lead to an increase in appendicitis cases in Britain in the late 19th century by reducing children's exposure to enteric organisms, leading to an altered immune response to viral infections $[1,3,4]$.

The presentation of a temporal progression of acute central abdominal pain shifting to the right lower quadrant, associated with vomiting, subsequent mild fever and signs of peritoneal irritation, is diagnostic of appendicitis [3]. Laboratory inflammation makers complement the diagnostic tools, with reliance on clinical indicators alone resulting in a negative appendicectomy rate of $15 \%$ or higher, especially in women. The differential diagnosis includes various non-surgical and gynecological conditions, requiring careful consideration, with delay in diagnosis results in increased morbidity, such as perforation, and mortality.

In an attempt to improve diagnostic accuracy, the Alvarado scoring system, which uses six clinical and two laboratory features, was developed. A score of 0 to 4,5 to 6,7 to 8 , and 9 to 10 suggests that the diagnosis of appendicitis is unlikely, possible, probable and definite, respectively [5]. Ultrasound and Computed Tomography (CT) scanning play a key role in reducing the higher 
rate of negative appendicectomy. CT scan is the most sensitive and accurate diagnostic method, but its specificity is similar to that of the ultrasound [6]. In cases of diagnostic uncertainty with a low suspicion index of appendicitis, conservative management, which includes hospitalisation and active clinical and laboratory observation, is an acceptable approach [3,7].

Kong et al. [8,9] validated the Alvarado score and in separate study, they evaluated the cost of managing appendicitis cases in Eden dale Hospital, a regional public sector hospital in Pietermaritzburg, South Africa. However, the profile of appendicitis patients, and the surgical procedures they underwent in Grey's Hospital have not been fully studied. Current trends support an increased use of minimally invasive surgery for both diagnostic and therapeutic purposes, especially for women. The patients' profile and clinical features influence the surgical management practices and the outcome. The surgical approaches utilized in Grey's Hospital are also largely unknown. This information will help in improving patients' care and benchmarking the institution against best practices and current trends; hence the relevance of undertaking this study.

\section{Objectives}

The study aimed to determine the demographic and clinical profile of patients treated for appendicitis, the commonest surgical approaches used for appendicectomy, the prevalence of post-operative complications, the prevalence of inaccurate diagnosis as demonstrated by the rate of histologically normal appendices, and the association between perforated appendix and, the age and gender of patients presenting with diagnosed acute appendicitis in Grey's Hospital.

\section{Methods}

In a retrospective cross-sectional survey, we reviewed medical records of 196 patients who were operated for appendicitis between January 2011 and June 2012 in Grey's Hospital, a tertiary hospital situated in Pietermaritzburg, South Africa. Theatre and laboratory registers were also reviewed to ensure completeness and accuracy of data. Variables collected included demographic data, surgical access, surgical procedure performed, complications, histology results and admission to intensive care unit (ICU). In this hospital, the diagnosis of appendicitis made by junior doctors is confirmed by a more experienced doctor before the patients are subjected to surgery.

Appendicectomy is carried out by a surgeon, registrar or an experienced Medical Officer, while postoperative management and follow up is done according to predetermined clinical guidelines, individualized according to each patient's clinical presentation. Data was collected using a structured data collection sheet and analyzed using IBM-SPSS version 21 software. Frequency tables, Chi-square test of independence and logistic regression were computed to determine the prevalence of certain characteristics and establish association between the variables. Ethical approval for the study, and permission to use hospital records were obtained from relevant bodies of Pietermaritzburg Hospitals Complex. The imperative to obtain informed consent from individual patients was waved as this was a retrospective medical records review. At the time of data collection, all patients were either discharged or had died.

\section{Results}

Hundred and ninety six patients' records were reviewed, of which $53.1 \%$ were for male patients. The mean age of participants was 21.1 years (SD: 12.6), the range was 2-67years, and the majority $(57.7 \%)$ of patients were $<20$ years. (Figure 1 ) shows that the gender distribution varied among the age groups, with more males in the younger age group ( $<20$ years) but more females in the age group 20-29 years.

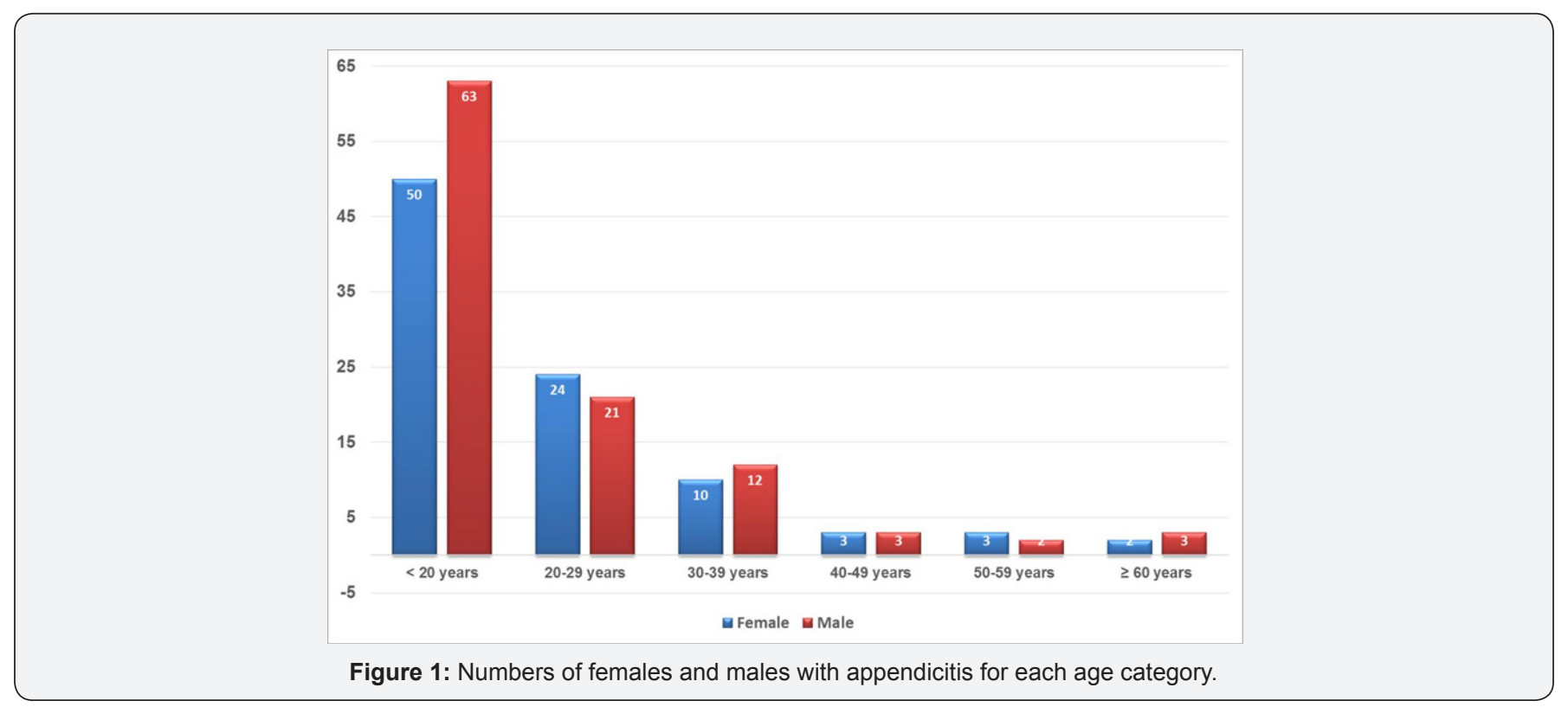




\section{Open Access Journal of Surgery}

With respect to the prevalence of the clinical variables, the majority of patients had histology results that confirmed the diagnosis of acute appendicitis. The commonest surgical approach was the lower midline incision. Although most patients were discharged alive, one died, 19 were admitted to ICU, and three required bowel resection. Of the 15 patients who had a normal appendix on their histology report, 11 (73.3\%)

Table 1: Clinical Characteristics of participants $(N=196)$.

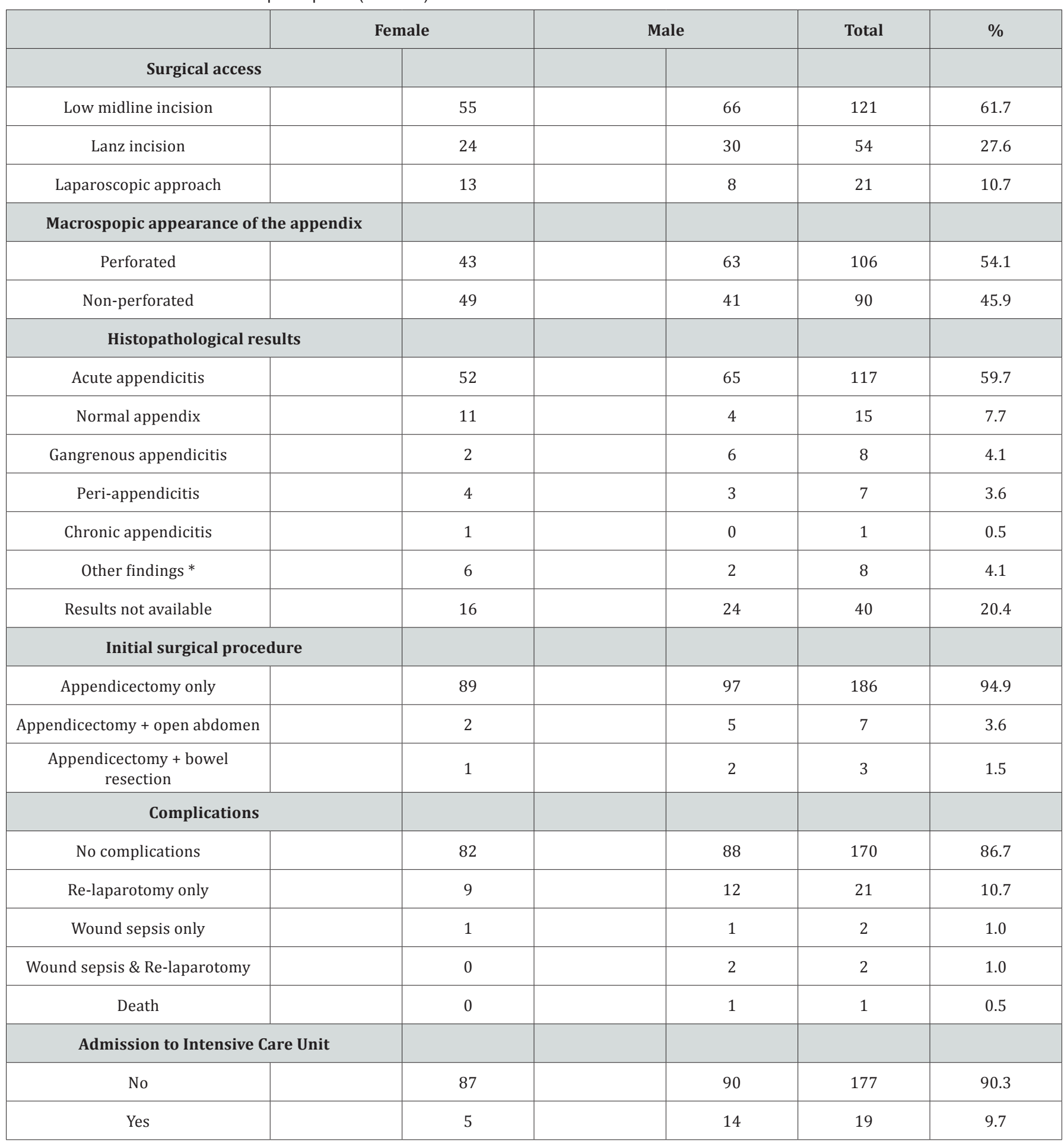

${ }^{*}$ Other findings include fecalith, parasites such as schistosomiasis, lymphadenopathy, and tuberculosis.

were females. Other clinical characteristics of the participants are presented in (Table 1). A univariate analysis of dependency showed no statistically significant association between 'gender' and all clinical variables. However, there were statistically nificant associations 2, 10, 12-10-13, 2, 8, 9 between 'age category' and 'complications', 'ICU admission' and 'initial surgical procedure performed' (Table 2). 


\section{Open Access Journal of Surgery}

Table 2: Univariate analysis between Gender or Age categories and clinical variables.

\begin{tabular}{|c|c|c|c|c|}
\hline \multirow[t]{2}{*}{ Clinical variables } & \multicolumn{2}{|c|}{ Gender } & \multicolumn{2}{|c|}{ Age category } \\
\hline & Chi-square & p-value & Chi-square & $\mathrm{p}$-value \\
\hline Histology & 10.76 & 0.96 & 32.98 & 0.95 \\
\hline Surgical access & 2.13 & 0.34 & 22.43 & 0.13 \\
\hline Complications & 2.91 & 0.57 & 69.30 & 0.00 \\
\hline ICU Admission & 3.59 & 0.05 & 17.18 & 0.02 \\
\hline Macroscopic finding & 3.76 & 0.05 & 8.29 & 0.40 \\
\hline Initial surgical procedure & 1.23 & 0.54 & 48.64 & 0.00 \\
\hline
\end{tabular}

*ICU: Intensive Care Unit

A logistic regression performed to ascertain the effects of age and gender on the likelihood of a participant having a perforated appendicitis showed no statistical significance, $\chi 2$ (2) $=11.7, p=0.16$. The model explained only $2.5 \%$ (Nagelkerke

classified $57.1 \%$ of cases. Males were 0.57 times (meaning a protective factor) more likely to have perforated appendicitis than females ( $\mathrm{p}=0.054$, marginally not significant). Increasing age was not associated with an increased likelihood of perforated R2) of the variance in perforated appendicitis and correctly appendicitis (Table 3).

Table 3: Odds Ratio for Age and Gender with "Perforation Status" as dependent variable.

\begin{tabular}{|c|c|c|c|c|c|c|c|c|}
\hline & \multirow{2}{*}{ B } & \multirow{2}{*}{ S.E. } & \multirow{2}{*}{ Wald } & \multirow{2}{*}{ df } & \multirow{2}{*}{ Sig. } & \multirow{2}{*}{$\operatorname{Exp}(B)$} & \multicolumn{2}{|c|}{ 95\% CI for EXP(B) } \\
\hline & & & & & & & Lower & Upper \\
\hline Age & 0.000 & 0.011 & 0.001 & 1 & 0.972 & 1.000 & 0.978 & 1.023 \\
\hline Gender(1) & -0.560 & 0.290 & 3.724 & 1 & 0.054 & 0.571 & 0.324 & 1.009 \\
\hline Constant & 0.122 & 0.326 & 0.140 & 1 & 0.708 & 1.130 & & \\
\hline
\end{tabular}

Variable(s) entered on step 1: Age, Gender.

\section{Discussion}

The mean age of our study participants was similar to that observed in other South African studies [2,8,9]. The predominance of males in the sample, although in keeping with findings in other studies [2,10-13], was not statistically significant $(\mathrm{p}=0.054)$. Patients who were $<20$ years old accounted for $57.7 \%$ of the sample, which suggests that appendicitis is more common in younger patients $[2,10,12-14]$. The high number of younger patients presents a multiple challenges to the clinicians, as children are believed to have thin-walled appendices that are predisposed to perforation, leading to increased morbidity and/ or mortality. Children are also unable to give a reliable history and to cooperate fully during physical examination $[15,16]$. They commonly suffer from other comorbidities, such as upper respiratory infection, otitis media or gastroenteritis, making their clinical picture complicated, leading to a delay in diagnosis.

Similar to children under three years, appendicitis is the cause of severe morbidity and mortality in elderly patients $[17,18]$. The perforation rate in this study was $54.1 \%$ which is in keeping with the findings of Roger et al. [19] in the Eastern Cape. In contrast, $9.7 \%$ of our patients required ICU admission postsurgery versus $6.1 \%$ of patients in Prince Mshiyeni Memorial Hospital in Durban [12]. The preference of the midline incision in $61.7 \%$ of cases is well justified in the light of the high rate of perforated appendicitis (54.1\%). Laparoscopic appendicectomy was used selectively in non-perforated appendices and in cases of diagnostic dilemma, as suggested by Ogbonna et al. [20]. The commonest incisions in Prince Mshiyeni Memorial Hospital were: lower midline laparotomy (47.2\%), gridiron incision $(37.3 \%)$, the combination of lower midline and gridiron incisions (5.6\%), and laparoscopic surgery or long midline or Lanz incision (5.5\%) [12]. These results may suggest a high rate of delayed presentation and/or complicated appendicitis. While these figures are in keeping with those found in this study, a study in the United Kingdom revealed a very low rate of open laparotomy of $10 \%$ [21].

The histologicalfinding of normal appendix was morecommon in women; therefore the liberal use of imaging techniques, particularly ultrasound, and laparoscopic exploration should be encouraged in women. In a randomized study, Larsson et al. [22] showed that a negative appendicectomy rate of $34 \%$ with open appendicectomy could be reduced to $7 \%$ through the prior use of laparoscopy. In those patients who did not have appendicitis, a definitive gynaecologic diagnosis was made in $73 \%$ compared with only $17 \%$ who had open appendicectomy alone [22]. A study by Blisard et al. [23] showed that after implementing a clinical guideline recommending laparoscopic use prior to open laparotomy, a significant drop, from $31 \%$ to $23 \%$, in the rate of negative appendicectomy in women was noted. Increasingly, laparotomy is being replaced by laparoscopic diagnosis and surgery [24]. 
Laparoscopy allows the appendix to be found wherever it may lie. The technique of laparoscopic appendicectomy is similar to the open operation, enabling the appendix to be visualized and an appendicectomy performed if it is abnormal. While a laparoscopic appendicectomy gives a lower wound infection rate and may allow an earlier return to normal activities, it is a more technically demanding operation [24]. In the absence of perforation and laparoscopic equipment, a low skin [12] and 2, 12, 13 crease incision (Lanz incision) rather than the higher and more oblique one centered on McBurney's point is now favored as it gives a better cosmetic result.

Nonetheless, the advantages of laparoscopic versus open appendicectomy are not yet universally accepted. A Cochrane systematic review found that laparoscopic appendicectomy in adults, when compared to open surgery reduces wound infections, postoperative pain, length of hospital stay, and time taken to return to work. In the same review, the number of intraabdominal abscesses was higher after the laparoscopic surgery [25]. A recent review, however, found no significant differences between the two procedures, except higher quality of life scores at two weeks in the laparoscopic group. Kiriakopoulos et al. [26] reviewed post-operative complications on complicated appendicitis that were operated laparoscopically and found no wound sepsis or intra-abdominal abscesses. As the conversion to open surgery rate was only $4.8 \%,[27]$ the investigators recommended a laparoscopic approach even for complicated appendicitis.

At surgery, three types of appendicitis may be described: normal, simple acute and complicated (perforated and/or gangrenous appendicitis and/or peri-appendicular abscess) [24]. Of the 196 specimens submitted for histopathology, 7.7\% were normal, 59.7\% showed features of acute appendicitis, $4.1 \%$ were gangrenous and $3.6 \%$ showed signs of peri-appendicitis. Notwithstanding the fact that there were no histological results for $20.4 \%$ of cases, the rate of negative appendicectomy $(7.7 \%)$ was similar to findings of other studies conducted in Africa $[2,12,13]$. Of the 15 patients who had normal appendix, 11 $(73.3 \%)$ were females. This highlights the need for pre-surgical laparoscopic diagnosis in women to exclude gynecological causes of localized or generalized abdominal pains. A Nigerian study found that incorrect diagnoses were more commonly encountered in females [11].

The majority of patients (94.9\%) had appendicectomy only, while $3.6 \%$ and $1.5 \%$ of patients had appendicectomy with the abdomen left open and with bowel resection respectively. These figures indicate that in most cases, the inflammation was limited to the appendix, suggesting that most of these cases could have benefited from laparoscopic surgery. Surgeons' preferences and/or lack of skills may have been a limitation to choosing laparoscopic surgery. Post-operative complications were observed in 26 patients (13.7\%), with 21 (10.7\%) necessitating a re-laparatomy, four (2\%) having wound sepsis, of whom two (1\%) required a re-laparotomy, and one $(0.5 \%)$ dying. Death accounted for $1.2 \%$ in Prince Mshiyeni Memorial Hospital [12]. The rate of post-operative infections in this study (2\%) was significantly lower than those obtained in a Durban hospital (25.3\%) in a Kenyan rural hospital (22\%) [28].

Although the Chi-square test of association did not reveal any statistically significant association between 'gender' and all clinical variables, there was an almost statistical significance between it and ICU admission" and "macroscopic findings". A statistically significant association between 'age categories' and 'complications', "ICU admission" and "the initial procedure performed" supports the finding of increased morbidity in extreme ages. Our model predicting the perforation status on the basis of gender and age revealed that being male was a marginally protective factor $(\mathrm{OR}=0.57 ; \mathrm{p}=0.05 ; 95 \% \mathrm{CI}=0.324$ - 1.009). It is not clear if infections from the gynaecologic tract played a role in this regard.

\section{Limitations of the study}

As with all retrospective charts review, some medical records had incomplete data which may have affected the findings. For example, the histology results were not available for $20.4 \%$ of cases. The study did not include cases that were taken to theatre for gynaecologic diagnosis that turned out to be appendicitis, as such patients might have had a pfannenstiel incision.

\section{Conclusion}

The majority of the patients reviewed present late with perforated appendicitis, resulting in midline laparotomy being the preferred surgical access despite the associated risk of additional morbidity. There is a need to develop skills in and encourage surgeons at this tertiary institution to perform minimally invasive surgery in cases of suspected appendicitis. The study has reaffirmed the difficulties in making the correct diagnosis in women, with $73.3 \%$ of patients with normal appendix being females. Judicious use of laparoscopy as an investigative and therapeutic tool may reduce the rate of negative laparotomy in women in particular.

\section{Conflict of Interest}

The study did not receive any external funding. The authors have no conflict of interest to declare.

\section{References}

1. Sulu B (2012) Demographic and Epidemiologic Features of Acute Appendicitis. Intech open science.

2. Madiba T, Haffejee A, Mbete D, Chaithram H, John J (1998) Appendicitis among African patients at King Edward VIII Hospital, Durban, SouthAfrica: a review. East Afr Med J 75(2): 81-84.

3. Macfarlane D, Thomas L (1984) Textbook of Surgery. (5 $5^{\text {th }}$ edn.), Churchille Livingstone, London, UK.

4. Walker ARP, Segal I (1995) Appendicitis: an African perspective. J R Soc Med 88(11): 616-619. 
5. MDCalc@ (2015) MDCALC.COM. Alvarado Score for Acute Appendicitis.

6. Chalazonitis AN, Tzovara I, Sammouti E, Ptohis N, Sotiropoulou E, et al. (2008) CT in Appendicitis. Diagn Interv Radiol 14(1): 19-25.

7. Banieghbal B, Lakhoo K (2000) Appendicitis. In: Ameh EA, Bickler SW, Lakhoo K, Nwomeh BC, Poenaru D, editors. Paediatric Surgery: A comprehensive Textbook for Africa. Vol. II. Seattle, WA, USA: The Global HELP Organization p: 440-442.

8. Kong V, C Aldous C, Handley J, Clarke D (2013) The cost effectiveness of early management of acute appendicitis underlies the importance of curative surgical services to a primary healthcare programme. Ann R Coll Surg Engl 95(4): 280-284.

9. Kong V, Van Der Linde S, Aldous C, Handley J, Clarke D (2014) The accuracy of the Alvarado score in predicting acute appendicitis in the black South African population needs to be validated. Can J Surg August 57(4): 121-125.

10. Addliss D, Shaffer N, Fowler BS, Tauxe RV (1990) The epidemiology of appendicitis and appendectomy in the United States. Am J Epidemiol 132(5): 910-925.

11. Ajao OG (1979) Appendicitis in a Tropical African Population. Journal of the National Medical Association 71(10): 997-999.

12. Chamisa I (2009) A clinicopathological review of 324 appendices removed for acute appendicitis in Durban, South Africa: a retrospective analysis. Ann R Coll Surg Engl 91(8): 688-692.

13. Kunle AE, Yinka OT, Oluyomi TA, Awodele AN (2011) Surgical pathologic review of appendectomy at a suburban tropical tertiary hospital in Africa. Journal of Medicine and Medical Science 2(6): 932938.

14. Walker ARP, Segal I (1979) Is Appendicitis Increasing in South African Blacks? S Afr Med J 503-504.

15. Alloo J, Gerstle T, Shilyansky J, Ein S (2004) Appendicitis in children less than 3 years of age: a 28-year review. Pediatric Surgery International 19(12): 777-779.
16. Aziz O, Athanasiou T, Tekkis P, Purkayastha S, Haddow J, et al. (2006) Laparoscopic versus open appendectomy in children: a meta-analysis. Annals of Surgery 243(1): 17-27.

17. Ostrow B (2006) Appendicitis 2006 [20 Feb 2015].

18. Williams RF, Blakely ML, Fischer PE, Streck CJ, Dassinger M, et al. (2009) Diagnosing Ruptured Appendicitis Preoperatively in Pediatric Patients. J Am Coll Surg 208(5): 819-825.

19. Rogers AD, Hampton Mi, Bunting M, Atherstone Ak (2008) Audit of appendicectomies at Frere Hospital, Eastern Cape. SAJS 46(3): 74-77.

20. Ogbonna BC, Obekpa PO, Momoh jT, Ige JT (1993) Another look at acute appendicitis in tropical Africa: and the value of laparoscopy in diagnosis. Tropical doctor 23(2): 82-84.

21. Lansdown M, Gray A, Treasure T, Layer G (2006) Appendicectomy: who performs it, when and how? . Ann R Coll Surg Engl 88(6): 530-534.

22. Larsson P, Henriksson G, Olsson M, Boris J, Ströberg P, et al. (2001) Laparoscopy reduces unnecessary appendicectomies and improves diagnosis in fertile women. A randomized study. Surg Endosc 15(2): 200-202.

23. Blisard D, Rosenfeld J, Estrada F, Reed J (2003) Institutioning a clinical practice guideline to decrease the rate of normal appendectomies. American Surgeon 69(9): 796-798.

24. Humes DJ, Simpson J (2006) Acute appendicitis. BMJ 333: 530-534.

25. Sauerland S, Lefering R, Neugebauer E (2004) Laparoscopic versus open surgery for suspected appendicitis. Cochrane Collaboration 4: CD001546.

26. Sauerland S, Jaschinski T, Neugebauer EAM (2010) Laparoscopic versus open surgery for suspected appendicitis. (Review) Cochrane Collaboration 10: CD001546.

27. Kiriakopoulos A, Tsakayannis D, Linos D (2006) Laparoscopic Management of Complicated Appendicitis. JSLS 10(4): 453-456.

28. Willmore WS, Hill AG (2001) Acute Appendicitis in a Kenyan Rural Hospital. East Afr Med J 78(7): 355-357.

\section{Your next submission with Juniper Publishers} will reach you the below assets

- Quality Editorial service

- Swift Peer Review

- Reprints availability

- E-prints Service

- Manuscript Podcast for convenient understanding

- Global attainment for your research

- Manuscript accessibility in different formats

( Pdf, E-pub, Full Text, Audio)

- Unceasing customer service

Track the below URL for one-step submission https://juniperpublishers.com/online-submission.php 